Revista Brasileira de Agricultura Irrigada v.8, nº 3, p. 270 - 279, 2014

ISSN 1982-7679 (On-line)

Fortaleza, CE, INOVAGRI - http://www.inovagri.org.br

DOI: $10.7127 /$ rbai.v8n300210

Protocolo 210/13 - 23/12/2013 Aprovado em 26/04/2014

\title{
FREQUÊNCIAS DE FERTIRRIGAÇÃO NITROGENADA E FOSFATADA NA RENTABILIDADE ECONÔMICA DA MELANCIA
}

\author{
Carlos Newdmar Vieira Fernandes ${ }^{1}$, Benito Moreira de Azevedo ${ }^{2}$, Joaquim Raimundo do \\ Nascimento Neto ${ }^{3}$, Thales Vinícius de Araújo Viana ${ }^{4}$, José Bruno Rêgo de Mesquita ${ }^{5}$, Kleiton \\ Rocha Saraiva*6
}

\section{RESUMO}

A obtenção do lucro por uma empresa agrícola pode ser designada como seu principal objetivo, sendo necessário, então, o uso racional dos recursos disponíveis a fim de se obterem os mais altos níveis de rentabilidade. No entanto, a maioria dos trabalhos científicos não avalia a viabilidade financeira das tecnologias estudadas, havendo pouca informação sobre seus benefícios e custos de produção. Assim, esse trabalho teve como objetivo avaliar a influência de frequências de fertirrigação com nitrogênio e fósforo no desempenho econômico da melancia, por meio de dois experimentos realizados no sítio Paraguai, município de Cruz, Ceará, em área com solo Neossolo Quartzarênico, no período de 12 de outubro a 20 de dezembro de 2010. O delineamento adotado foi o de blocos ao acaso com seis tratamentos e quatro repetições. Os tratamentos foram: $2 \mathrm{~F}$ - 2 fertirrigações no ciclo; $4 \mathrm{~F}$ - 4 fertirrigações no ciclo; $8 \mathrm{~F}$ - 8 fertirrigações no ciclo; $16 \mathrm{~F}$ - 16 fertirrigações no ciclo; $32 \mathrm{~F}$ - 32 fertirrigações no ciclo e 64F - 64 fertirrigações no ciclo. Avaliou-se a receita líquida nos dois experimentos. Para a fertirrigação nitrogenada a maior receita líquida obtida foi de $(\mathrm{R} \$ 8.799,00)$ referente ao tratamento 64F. Enquanto que, para a fertirrigação fosfatada a maior receita líquida (R\$ $3.427,41$ ) foi obtida para o tratamento $32 \mathrm{~F}$. O parcelamento da fertirrigação com $\mathrm{N}$ e $\mathrm{P}$ aumentou a receita líquida tornando a atividade mais lucrativa e segura.

Palavras-chave: Citrullus lanatus, quimigação, receita líquida.

\footnotetext{
${ }^{1}$ Engenheiro Agrônomo. Doutorando em Engenharia Agrícola. Universidade Federal do Ceará. Campus do Pici, B1. 804 S/N. Planalto do Pici. CEP: 60455-760. Fortaleza-CE. newdmar@yahoo.com.br

2 Doutor em Agronomia. Depto. de Engenharia Agrícola, Bloco 804 UFC/Fortaleza - CE. E-mail: benitoazevedo@ufc.br

${ }^{3}$ Tecnólogo em Irrigação. Mestre em Engenharia Agrícola. Universidade Federal do Ceará. Campus do Pici, B1. 804 S/N. Planalto do Pici. CEP: 60455-760. Fortaleza-CE. Netoparaguai456@yahoo.com.br

${ }^{4}$ Doutor em Irrigação e Drenagem. Depto. de Engenharia Agrícola, Bloco 804 UFC/Fortaleza - CE. E-mail: Thales@ufc.br

${ }^{5}$ Engenheiro Agrônomo, Doutorando em Engenharia Agrícola - Depto. de Engenharia Agrícola, Bloco 804 UFC/Fortaleza - CE. E-mail: agronobruno@gmail.com

${ }^{6}$ Engenheiro Agrônomo, Doutorando em Engenharia Agrícola - Depto. de Engenharia Agrícola, Bloco 804 UFC/Fortaleza-CE. E-mail: kleitonagro@bol.com.br (Autor para correspondência).
} 


\title{
ECONOMIC PROFITABILITY OF WATERMELON IN DIFFERENT FREQUENCY FERTIRRIGATION WITH NITROGEN AND PHOSPHORUS
}

\begin{abstract}
Obtaining profit by an agricultural company can be designated as your primary goal, it is necessary, then, the rational use of available resources in order to achieve the highest levels of profitability. In order to evaluate the influence of different frequencies of fertigation with nitrogen and phosphorus in the economic performance of watermelon, two experiments were conducted at the site Paraguay, the Cruz, Ceará, in the period from October 12 to December 20, 2010. The study design was a randomized block design with six treatments and four replications. The treatments were: $2 \mathrm{~F}-2$ fertigation cycle; $4 \mathrm{~F}-4$ fertigation cycle; $8 \mathrm{~F}-8$ fertigation cycle; $16 \mathrm{~F}$ - 16 fertigation cycle; $32 \mathrm{~F}$ - 32 fertigation cycle and $64 \mathrm{~F}$ - 64 fertigation cycle. We evaluated the net in both experiments. Nitrogen fertigation for the highest net revenue obtained was ( $\mathrm{R} \$ 8,799.00$ ) for the treatment 64F. While, for fertigation phosphorus the highest net revenue ( $\mathrm{R} \$ 3,427.41)$ was obtained for the treatment 32F. The installment of fertigation with $\mathrm{N}$ and $\mathrm{P}$ increased the net making the activity more profitable and secure.
\end{abstract}

Keywords: Citrullus lanatus, chemigation, net revenues.

\section{INTRODUÇÃO}

A melancieira (Citrullus lanatus (Thunb.) Matsum \& Nakai) é uma das principais cucurbitáceas com elevada expressão na agricultura, sendo cultivada em várias partes do Brasil e do mundo. Seus frutos são bastante apreciados devido ao sabor refrescante, mesmo não apresentando alto valor nutritivo. Atualmente, a melancieira tem se destacado como uma das principais frutas em volume de produção mundial, estando dentre os dez produtos hortifrutícolas mais exportados (DIAS et al. 2001; ARAÚJO, 2009; ANDRADE, 2012).

O cultivo da melancieira na região Nordeste do Brasil exerce grande importância socioeconômica por ser cultivada, principalmente, por pequenos e médios agricultores. $\mathrm{O}$ manejo simples e menor custo de produção, quando comparada com outras hortaliças, como o melão, tomate, batata, pimentão, entre outros, aliados a demanda intensiva de mão-de-obra rural, geram renda e empregos, contribuindo para a manutenção do homem no campo, além de atrativo retorno econômico ao produtor, evidenciando a expressividade da cultura (ROCHA, 2010).

A época ideal para a produção de melancia no Ceará, com obtenção de frutos de melhor qualidade e maiores preços no mercado é de julho a dezembro. Esse período coincide com a estação seca, sendo assim, fundamental o uso da irrigação para suprir as necessidades hídricas da cultura (CARVALHO et al., 2007).

Aliado ao uso da irrigação outro aspecto bastante relevante para o incremento na produtividade da melancieira é a prática da adubação, esta atividade quando realizada corretamente incrementa a produtividade e, com efeito, a rentabilidade da lavoura (NOBRE, 2007). 
Como em outras culturas, a melancieira depende da nutrição mineral equilibrada e constitui um dos fatores que contribuem diretamente para produtividade e qualidade dos frutos, destacando-se por ser altamente exigente em nitrogênio, o que aumenta a necessidade de pesquisa sobre o macronutriente (ANDRADE JÚNIOR et al., 2006).

$\mathrm{O}$ fósforo $(\mathrm{P})$ trata-se de outro nutriente essencial no metabolismo das plantas, desempenhando papel importante na transferência de energia da célula, na respiração e na fotossíntese. Limitações na disponibilidade de P, no início do ciclo vegetativo, podem resultar em restrições no desenvolvimento, das quais a planta não se recuperam posteriormente, mesmo aumentando o suprimento de $\mathrm{P}$ para níveis adequados. essa situação exige suprimento adequado de $\mathrm{P}$ desde os estádios iniciais de crescimento da planta (GRANT et al., 2001).

A fertirrigação tem sido uma ótima alternativa à aplicação convencional de nutrientes sobre a superfície do solo, pois quando o fertilizante é dissolvido na água fica prontamente disponível, podendo ser absorvido assim que entra em contato com o sistema radicular das plantas (SANTORO et al., 2013).

$\mathrm{O}$ uso da fertirrigação proporciona aumentos na eficiência da adubação, principalmente quando se faz uso da irrigação localizada, onde geralmente há uma restrição do sistema radicular da planta à zona molhada pelo emissor, tendo com isso um requerimento constante pelos nutrientes para manter a produção (FERNANDES; PRADO, 2004). Para Papadopoulos (1999), o parcelamento da adubação durante o ciclo das culturas e sua aplicação diretamente na zona efetiva do sistema radicular pode aumentar à eficiência de utilização. Para Santos et al. (2009), a busca constante por um equilíbrio na aplicação de nitrogênio $(\mathrm{N})$, aliada a escassez de estudos sobre a resposta da planta, aumenta a necessidade de mais investigação sobre o assunto.

No que diz respeito à fertirrigação fosfatada, a maioria dos adubos podem causar obstruções de emissores e incrustações nas canalizações, podendo a solução para este problema estar na utilização do ácido fosfórico (FORATTO et al., 2007). No entanto, sua aplicação contribui para o aumento da acidez do solo, principalmente na região próxima ao gotejador (ZANINI et al., 2007).

Desta forma, fica clara a necessidade de investigação na busca por estratégias de manejo que possibilitem a adoção do ácido fosfórico na fertirrigação da melancia. Assim, o presente trabalho teve como objetivo avaliar os efeitos de frequências de fertirrigação com nitrogênio e fósforo no desempenho produtivo e econômico da cultura da melancia.

\section{MATERIAL E MÉTODOS}

Os experimentos foram conduzidos simultaneamente de outubro a dezembro de 2010, no sítio Paraguai, município de Cruz, localizado na região Norte do estado do Ceará, a $02^{\circ} 54$ '25' 'S, $40^{\circ} 24^{\prime} 21^{\prime \prime} \mathrm{W}$ e a $19 \mathrm{~m}$ de altitude. De acordo com a classificação climática de Köppen, o clima da região é do tipo Aw', caracterizado como clima tropical chuvoso, com precipitação 
média anual de $900 \mathrm{~mm}$, temperatura média de $28,8^{\circ} \mathrm{C}$ e umidade relativa média anual de $70 \%$ (SARAIVA, 2010).

O solo da área é classificado em Neossolo Quartzarênico, com relevo leve, bem drenado e de textura arenosa, com os atributos químicos e físicos, na camada de 0 a $20 \mathrm{~cm}$, indicados na Tabela 1.

Tabela 1. Características físico-químicas do solo na profundidade $(0-20 \mathrm{~cm})$ na área experimental, Cruz, Ceará, 2010.

\begin{tabular}{|c|c|c|c|}
\hline Análise Química & $\begin{array}{c}(0-20 \\
\mathrm{cm})\end{array}$ & Análise Física & $\begin{array}{c}(0-20 \\
\mathrm{cm})\end{array}$ \\
\hline $\mathrm{PO}_{4}^{3-}\left(\mathrm{mg} \mathrm{dm}^{-3}\right)$ & 2,0 & Areia fina $\left(\mathrm{g} \mathrm{kg}^{-1}\right)$ & 248 \\
\hline $\mathrm{K}^{+}\left(\mathrm{cmol}_{\mathrm{c}} \mathrm{dm}^{-3}\right)$ & 0,1 & Areia grossa $\left(\mathrm{g} \mathrm{kg}^{-1}\right)$ & 675 \\
\hline $\mathrm{Na}^{+}\left(\mathrm{cmol}_{\mathrm{c}} \mathrm{dm}^{-3}\right)$ & 0,06 & Silte $\left(\mathrm{g} \mathrm{kg}^{-1}\right)$ & 36 \\
\hline $\mathrm{Ca}^{2+}\left(\mathrm{cmol}_{\mathrm{c}} \mathrm{dm}^{-3}\right)$ & 0,8 & Argila $\left(\mathrm{g} \mathrm{kg}^{-1}\right)$ & 41 \\
\hline $\mathrm{Mg}^{2+}\left(\mathrm{cmol}_{\mathrm{c}} \mathrm{dm}^{-3}\right)$ & 0,6 & Argila natural $\left(\mathrm{g} \mathrm{kg}^{-1}\right)$ & 17 \\
\hline $\mathrm{Al}^{3+}\left(\mathrm{cmol}_{\mathrm{c}} \mathrm{dm}^{-3}\right)$ & 0,2 & $\begin{array}{l}\text { Massa específica } \\
\qquad\left(\mathrm{g} \mathrm{cm}^{-3}\right)\end{array}$ & 1,52 \\
\hline $\begin{array}{c}\mathrm{H}^{+}+\mathrm{Al}^{3+} \\
\left(\mathrm{cmol}_{\mathrm{c}} \mathrm{dm}^{-3}\right)\end{array}$ & 1,82 & Floculação $\left(\mathrm{g} 100 \mathrm{~g}^{-1}\right)$ & 58 \\
\hline CTC $\left(\mathrm{cmol}_{\mathrm{c}} \mathrm{dm}^{-3}\right)$ & 3,38 & Água útil $\left({\left.\mathrm{g} 100 \mathrm{~g}^{-1}\right)}^{-1}\right.$ & 0,48 \\
\hline $\mathrm{pH}$ & 4,9 & Classe textural & Areia \\
\hline $\mathrm{CE}\left(\mathrm{dS} \mathrm{m} \mathrm{m}^{-1}\right)$ & 0,21 & & \\
\hline $\operatorname{PST}(\%)$ & 1,78 & & \\
\hline
\end{tabular}

Fonte: Laboratório de Solos e Água do Departamento de Ciências do Solo do CCA/UFC.

De acordo com a análise realizada, a água de irrigação foi classificada como $C_{1} S_{1}$, não oferecendo limitações à prática da irrigação, conforme os índices recomendados pela FAO (AYERS; WESTCOT, 1999).

$\mathrm{O}$ delineamento estatístico utilizado foi o de blocos casualizados, composto por seis tratamentos e quatro repetições. Os tratamentos consistiram em seis frequências de fertirrigação com nitrogênio e fósforo, sendo: $2 \mathrm{~F}-2$ fertirrigações no ciclo; 4F - 4 fertirrigações no ciclo; 8F - 8 fertirrigações no ciclo; $16 \mathrm{~F}$ - 16 fertirrigações no ciclo; 32F - 32 fertirrigações no ciclo; 64F - 64 fertirrigações no ciclo. Todos os tratamentos tiveram início no dia do plantio e as demais aplicações ao longo do ciclo da cultura da seguinte forma: $2 \mathrm{~F}$ - (0 e $32 \mathrm{DAP})$; $4 \mathrm{~F}$ - $(0 ; 16 ; 32$ e 48 DAP $) ; 8 \mathrm{~F}-(0 ; 8 ; 16 ; \ldots ; 48$ e 56 DAP $) ; 16 \mathrm{~F}$ - $(0 ; 4 ; 8 ; \ldots ; 56$ e 60 DAP $)$; $32 \mathrm{~F}$ - $(0 ; 2 ; 4 ; \ldots ; 60$ e 62 DAP $)$ e $64 \mathrm{~F}-(0 ; 1 ; 2$; ... ; 63 e 64 DAP). A parcela experimental foi constituída por 35 plantas espaçadas de 2,0 m entre fileiras e de 1,0 m entre plantas. Para a instalação da cultura realizou-se semeadura direta, colocando-se duas sementes por cova da variedade Crimson Sweet, sendo realizado o desbaste sete dias após a semeadura (DAS), deixando-se apenas um a planta por cova, perfazendo um estande de 5.000 plantas ha ${ }^{-1}$.

As quantificações dos fertilizantes a serem aplicados foram baseadas na análise de solo e nas recomendações propostas por Crisóstomo et al. (2002), preconizando a aplicação dos principais nutrientes de acordo com a marcha de absorção da cultura.

Todas as adubações foram realizadas via água de irrigação, empregando-se os seguintes adubos: ureia (120 $\mathrm{kg} \mathrm{ha}^{-1}$ de nitrogênio), nitrato de cálcio (68 $\mathrm{kg} \mathrm{ha}^{-1}$ de cálcio), ácido fosfórico (240 $\mathrm{kg} \mathrm{ha}^{-1}$ de $\mathrm{P}_{2} \mathrm{O}_{5}$ ), cloreto de potássio branco (300 kg ha- de $\mathrm{K}_{2} \mathrm{O}$ ), sulfato de magnésio (23 $\mathrm{kg} \mathrm{ha}^{-1}$ de magnésio), ácido bórico ( $1 \mathrm{~g}$ planta $^{-1}$ de boro) e sulfato de zinco ( 2 g planta $^{-1}$ de zinco).

Os tratos culturais constaram de duas capinas manuais aos 15 e 35 DAS; desbaste de frutos do $40^{\circ}$ ao $50^{\circ}$ DAS; monitoramento do estado fitossanitário e nutricional realizado 
durante todo o experimento e colheita manual realizada aos 69 DAS.

O sistema de irrigação adotado foi do tipo gotejamento, sendo constituído de uma linha lateral por fileira de planta. Cada linha lateral, composta de tubo gotejador de polietileno com gotejadores espaçados a $0,4 \mathrm{~m}$ e vazão nominal de $1,6 \mathrm{~L} \mathrm{~h}^{-1}$, apresentava $35 \mathrm{~m}$ de comprimento e estavam espaçadas em $2 \mathrm{~m}$ uma da outra. A lâmina de água aplicada nas irrigações, realizadas diariamente, foi estimada considerando a evapotranspiração da cultura (ETc) obtida a partir da evapotranspiração de referência (ETo), estimada por meio da evaporação de água em um tanque Classe "A" instalado anexo à área de cultivo, e do coeficiente de cultivo (Kc), conforme recomendação de Miranda et al. (2004), para cada estádio de desenvolvimento da planta.

Ao final do ciclo da cultura mensurou-se a produtividade comercial (PC) e realizou-se a análise de rentabilidade econômica por meio de cálculo da receita líquida para cada tratamento.

Para realização da análise de rendimento econômico, foram levantados os preços dos insumos em lojas agropecuárias de Fortaleza, em setembro de 2011. Considerou-se o preço do quilograma de melancia praticado na compra pelos comerciantes da CEASA - Ceará e para o custo referente à eletricidade foi utilizado o preço do $\mathrm{kW} \mathrm{h}^{-1}$ rural.

A partir da produtividade de cada tratamento, calculou-se a respectiva receita líquida, utilizando a planilha eletrônica adaptada de Souza (2006), a fim de se verificar o retorno econômico para o produtor. O custo cultural $\left(\mathrm{CC}\right.$, em $\mathrm{R} \$ \mathrm{ha}^{-1}$ ) foi calculado pela seguinte fórmula:

$$
\mathrm{CC}=\mathrm{SE}+\mathrm{FE}+\mathrm{AG}+\mathrm{EE}+\mathrm{OME}+\mathrm{OMA}(01)
$$

Onde:

SE - sementes $\left(\mathrm{R} \$ \mathrm{ha}^{-1}\right)$;

$\mathrm{FE}$ - fertilizantes $\left(\mathrm{R} \$ \mathrm{ha}^{-1}\right)$;

$\mathrm{AG}$ - agrotóxicos $\left(\mathrm{R} \$ \mathrm{ha}^{-1}\right)$;

$\mathrm{EE}$ - energia elétrica $\left(\mathrm{R} \$ \mathrm{ha}^{-1}\right)$;

OME - operação mecanizada $\left(\mathrm{R} \$ \mathrm{ha}^{-1}\right)$;

OMA - operação manual $\left(\mathrm{R} \$ \mathrm{ha}^{-1}\right)$.

Posteriormente, calculou-se o custo total (CT) com a Equação 02.

$$
\mathrm{CT}=\mathrm{CC}+\mathrm{CA}+\mathrm{EI}+\mathrm{JC}
$$

Onde:

$\mathrm{CA}$ - custos administrativos $\left(\mathrm{R} \$ \mathrm{ha}^{-1}\right)$;

$\mathrm{EI}$ - equipamento de irrigação $\left(\mathrm{R} \$ \mathrm{ha}^{-1}\right)$;

$\mathrm{JC}$ - juros sobre custeio anual $\left(\mathrm{R} \$ \mathrm{ha}^{-1}\right)$.

Por fim, com as Equações 03 e 04, calculou-se a receita bruta $\left(\mathrm{RB}, \mathrm{em} \mathrm{R} \$ \mathrm{ha}^{-1}\right)$ e a receita líquida ( $\mathrm{RL}, \mathrm{em} \mathrm{R} \$ \mathrm{ha}^{-1}$ ).

$$
\begin{aligned}
& \mathrm{RB}=\mathrm{PC} \times \text { PREÇO } \\
& \mathrm{RL}=\mathrm{RB}-\mathrm{CT}
\end{aligned}
$$

Onde:

$\mathrm{PC}$ - produtividade comercial $\left(\mathrm{R} \$ \mathrm{ha}^{-1}\right)$;

PREÇO - preço $\left(\mathrm{R} \$ \mathrm{ha}^{-1}\right)$;

$\mathrm{CT}$ - custo total $\left(\mathrm{R} \$ \mathrm{ha}^{-1}\right)$.

Os dados de produtividade comercial foram submetidos a análise de variância pelo teste $\mathrm{F}$ aos níveis d e 1 e $5 \%$ de probabilidade e de regressão utilizando o software SAEG 9.0 UFV. 


\section{RESULTADOS E DISCUSSÃO}

As frequências de fertirrigação (Tabela 2) exerceram efeitos significativos $(p<0,01)$ sobre a produtividade comercial (PC) da melancieira, de ambos os experimentos.

Tabela 2. Resumo das análises de variância, com base no quadrado médio, para produtividade comercial (PC) em plantas de melancia, em função da frequência de fertirrigação com nitrogênio (FN) e fósforo (FF), Cruz, Ceará, 2010.

\begin{tabular}{|c|c|c|c|}
\hline \multirow[t]{2}{*}{ FV } & \multicolumn{3}{|c|}{ Quadrado Médio } \\
\hline & GL & $\mathrm{FN}$ & $\mathrm{FF}$ \\
\hline Tratamento & 5 & $600,13 * *$ & $310,12 * *$ \\
\hline Bloco & 3 & $26,13^{(\mathrm{ns})}$ & $0,44 * *$ \\
\hline Resíduo & 15 & 77,03 & 31,83 \\
\hline Total & 23 & - & - \\
\hline $\mathrm{CV}(\%)$ & - & 14,26 & 9,69 \\
\hline
\end{tabular}

Por meio da análise de regressão verificou-se que, para explicar o comportamento da variável em função das diferentes frequências de fertirrigação o modelo linear apresentou-se como o mais adequado para ambos os casos, tendo proporcionado efeito significativo de $1 \%(\mathrm{P}<0,01)$ com coeficientes de determinação $\left(\mathrm{R}^{2}\right)$ de 0,93 e 0,66 , respectivamente para nitrogênio e fósforo (Figuras 1A e 1B).

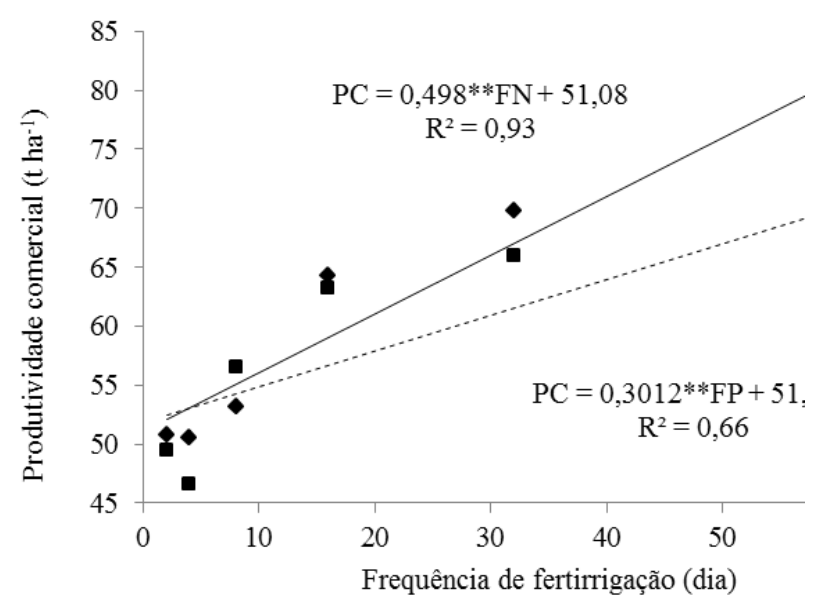

Figura 1. Produtividade comercial da cultura da melancia em função da frequência de fertirrigação com nitrogênio e fósforo, Cruz, Ceará, 2010.

A produtividade comercial da melancieira aumentou linearmente com o aumento das frequências da fertirrigação, atingindo os valores estimados de 83 e 71 t ha $^{-1}$, respectivamente para fertirrigação nitrogenada (FN) e fosfatada (FP), ambos com o tratamento de fertirrigação diária (64F). Estas produtividades estão próximas daquelas relatadas por Andrade Júnior et al. (2007) e Morais et al. (2008), com colheitas de 76 e $78 \mathrm{t}$ $\mathrm{ha}^{-1}$, respectivamente, ao irrigarem a cultura da melancia por gotejamento.

Tendência semelhante corroborando foi registrada por Pinto et al. (1994), ao trabalharem com meloeiro e constatarem, diferenças significativas da frequência de fertirrigação nitrogenada por gotejamento na produção comercial. Segundo esses autores, a frequência diária proporcionou os maiores resultados $\left(20 \mathrm{t} \mathrm{ha}^{-1}\right)$, quando comparada com a frequência a cada três dias. Andrade Júnior et 
al. (2007) relatam que, para diversas espécies oleráceas, parcelamento da fertirrigação tem proporcionado maiores incrementos na produtividade, como evidenciado no estudo em apreço.

Pela receita líquida resultante da análise econômica simplificada em função das diferentes frequências de fertirrigação com nitrogênio e fósforo aos 69 DAS, observa-se que todos os tratamentos apresentaram receitas líquidas positivas, ou seja, retorno de capital investido pelo produtor (Figura 2).
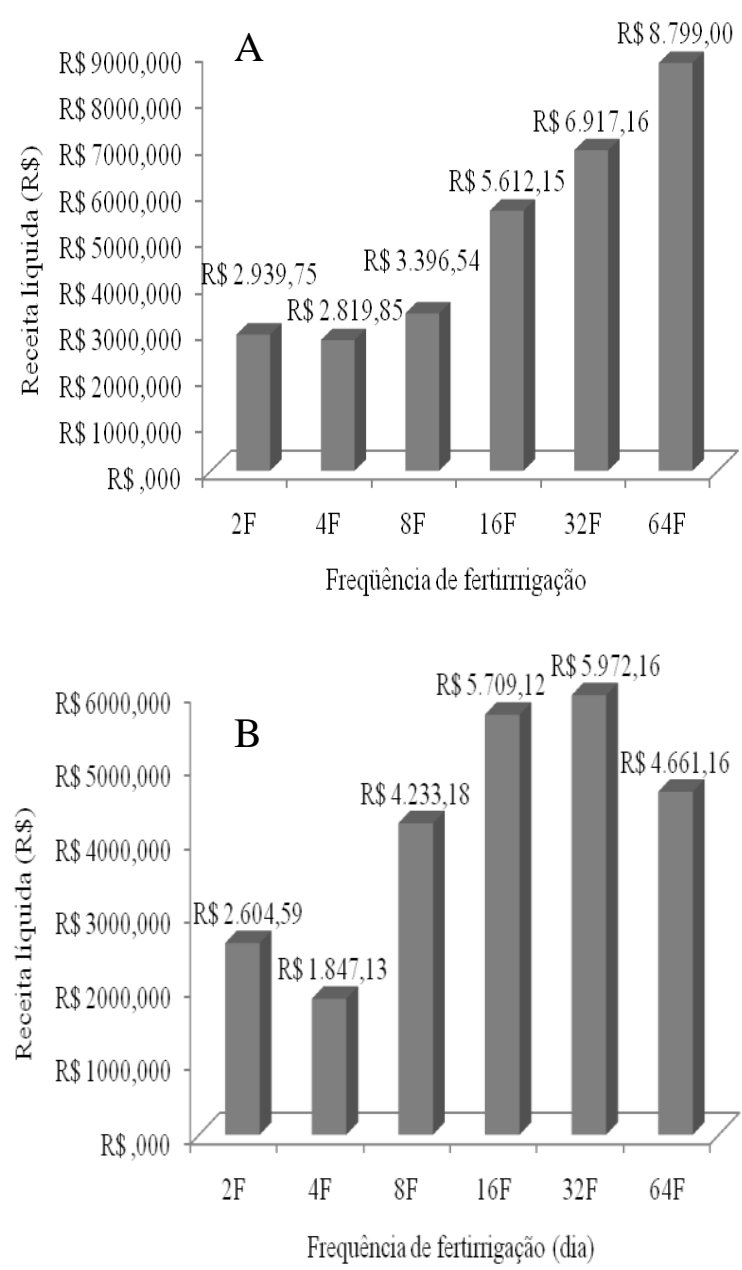

Figura 2. Receita líquida, em reais (R\$), da produtividade da melancieira em função da frequência de fertirrigação com nitrogênio (A), e frequência de fertirrigação com fósforo (B), Cruz, Ceará, 2010.

Os valores das receitas líquidas positivas referentes à fertirrigação com nitrogênio (Figura 2A) apresentaram comportamento de ordem crescente atingindo o maior valor $(\mathrm{R} \$ 8.799,00)$ para o tratamento com maior frequência de aplicação 64F.

Para a receita líquida resultante da análise econômica simplificada em função das diferentes frequências de fertirrigação com fósforo aos 69 DAS (Figura 2B). Pode-se perceber que, entre todos os tratamentos, foram constatados valores de receita positivos para a receita líquida. Observa-se que a maior receita líquida, R\$ 5.972,16 foi obtida com o tratamento $32 \mathrm{~F}$.

Segundo Araújo et al. (2004), o segmento dos insumos é o que mais onera os custos operacionais da exploração da cultura da melancia, $61 \%$ desses custos, e os adubos químicos são responsáveis por 39,23\% deles. A importância da eficiência do uso dos fertilizantes químicos é visível e os resultados da análise econômica evidenciam que o parcelamento da adubação, por meio da fertirrigação, trata-se de uma alternativa viável como meta por ganhos de produtividade e de receita ao produtor para cultivos em solos com textura arenosa.

$\mathrm{O}$ fornecimento adequado de nutrientes contribui de forma significativa tanto no aumento da produtividade, quanto na diminuição dos custos de produção. Nesta situação, a otimização da eficiência nutricional é fundamental para ampliar a produtividade e reduzir os custos de produção (FAGERIA, 1998). Pelas análises econômicas apresentadas, pode-se inferir que, quando se visa uma maior 
rentabilidade em termos de lucro para o produtor, a aplicação do adubo fosfatado deve ser feita de forma fracionada, e que se utilizando 32 aplicações distribuídas ao longo do ciclo da cultura obtém-se maior rendimento econômico.

$\mathrm{Na}$ Tabela 3 pode-se visualizar $\mathrm{o}$ comparativo entre a produtividade e a receita líquida para cada tratamento de fertirrigação nitrogenada e fosfatada. Observa-se que, no caso da fertirrigação nitrogenada a maior receita líquida correspondeu ao tratamento (64F) que proporcionou também maior produtividade, fato esse não observado para a fertirrigação com fósforo situação em que o tratamento (64F) de maior produtividade não proporcionou a maior receita líquida $(32 \mathrm{~F})$.

Tabela 3.Valores de produtividade comercial e receita líquida da cultura da melancia em função das frequências de fertirrigação com nitrogênio e fósforo, Cruz, Ceará, 2010.

\begin{tabular}{|c|c|c|c|c|}
\hline \multirow{2}{*}{ 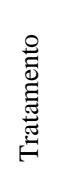 } & \multicolumn{2}{|c|}{ Fertirrigação nitrogenada } & \multicolumn{2}{|c|}{ Fertirrigação fosfatada } \\
\hline & $\begin{array}{c}\mathrm{PC} \\
\left(\mathrm{t} \mathrm{ha}^{-1}\right)\end{array}$ & $\begin{array}{c}\mathrm{RL} \\
(\mathrm{R} \$)\end{array}$ & $\begin{array}{c}\mathrm{PC} \\
\left(\mathrm{t} \mathrm{ha}^{-1}\right)\end{array}$ & $\begin{array}{c}\mathrm{RL} \\
(\mathrm{R} \$)\end{array}$ \\
\hline $2 \mathrm{~F}$ & 50,75 & $\mathrm{R} \$ 2.939,75$ & 49,42 & $\mathrm{R} \$ 2.604,59$ \\
\hline $4 \mathrm{~F}$ & 50,49 & $\mathrm{R} \$ 2.819,85$ & 46,63 & $\mathrm{R} \$ 1.847,13$ \\
\hline $8 \mathrm{~F}$ & 53,21 & $\mathrm{R} \$ 3.396,54$ & 56,53 & $\mathrm{R} \$ 4.233,18$ \\
\hline $16 \mathrm{~F}$ & 64,31 & $\mathrm{R} \$ 5.612,15$ & 63,25 & $\mathrm{R} \$ 5.709,12$ \\
\hline $32 \mathrm{~F}$ & 69,77 & $\mathrm{R} \$ 6.917,16$ & 66,02 & $\mathrm{R} \$ 5.972,16$ \\
\hline $64 \mathrm{~F}$ & 80,69 & $\mathrm{R} \$ 8.799,00$ & 67,54 & $\mathrm{R} \$ 4.661,16$ \\
\hline
\end{tabular}

No caso da fertirrigação com ácido fosfórico, a redução da receita líquida observada para o tratamento $64 \mathrm{~F}$, em relação aos tratamentos $32 \mathrm{~F}$ e $16 \mathrm{~F}$, pode está associada ao custo da mão de obra para aplicação das frações da dose do adubo, já que para essa condição este custo é maior devido ao maior número de fertirrigações, embora a produtividade comercial tenha sido superior. Pode-se então afirmar que o aumento da produtividade ocasionado pelo parcelamento da dose em 64 aplicações não foi o suficiente para cobrir os custos resultando em queda de rentabilidade da cultura.

\section{CONCLUSÕES}

O parcelamento da fertirrigação com nitrogênio e fósforo, em solo de textura arenosa, aumenta a receita líquida da melancieira. A fertirrigação nitrogenada proporcionou receita líquida de $(\mathrm{R} \$ 8.799,00)$ referente ao tratamento com 64 fertirrigações e da fertirrigação fosfatada ( $\mathrm{R} \$ 5.972,16)$ para o tratamento com 32 fertirrigações no ciclo.

\section{REFERÊNCIAS}

ANDRADE JÚNIOR, A. S. de; DIAS, N. DA S.; FIGUEIREDO JÚNIOR, L. G. M.; RIBEIRO, V. Q.; SAMPAIO, D. B. Produção e qualidade de frutos de melancia à aplicação de nitrogênio via fertirrigação. Revista Brasileira de Engenharia Agrícola e Ambiental, Campina Grande, v. 10, n. 4, p. 836-841, 2006.

ANDRADE JÚNIOR, A. S. de; DIAS, N. DA S.; LIRA, R. B. DE; FIGUEREDO JUNIOR, L. 
G. M.; DANIEL, R. Frequência de aplicação de nitrogênio e de potássio via água de irrigação por gotejamento na cultura da melancia em Parnaíba, PI. Agropecuária Científica no Semiárido, Campina Grande, v. 03, p. 01-07, 2007.

ANDRADE, P. F. DE S. Análise da conjuntura agropecuária safra 2011/12 fruticultura. Estado do Paraná Secretaria da Agricultura e do Abastecimento - Departamento de Economia Rural. 9p, 2012.

ARAÚJO, J. L. P. Custos e viabilidade de produção de melancia na região do submédio São Francisco, 2009. Disponível em: <http://www.todafruta.com.br/portal/icNoticiaA berta.asp?idNoticia $=18641>$. Acesso em: 11/08/2013.

ARAÚJO, J. L. P.; CORREIA, R. C.; COSTA, N. D.; RAMALHO, P. J. P. Análises dos custos de produção e rentabilidade da melancia produzida na região do submédio São Francisco. Horticultura Brasileira, Brasília, v. 22, n. 2, jul., 2004.

AYERS, R. S.; WESTCOT, D. W. A qualidade da água na agricultura. Campina Grande: UFPB, 1999. 153 p. (Estudos FAO: Irrigação e Drenagem, 29).

CARVAlHO, L. C. C. de; BEZERRA, F. M. L.; CARVALHO, M. A. R. de Evapotranspiração e coeficientes de cultivo da melancia sem sementes. Revista Ciência Agronômica, Fortaleza, v. 39, n. 01, p. 53-59, jan/mar. 2007.

CRISÓSTOMO, L. A.; SANTOS, A. A. dos; RAIJ, B. V.; FARIA, C. M. B. de; SILVA, D. J. da; FERNANDES, F. A. M.; SANTOS, F. J. de S.; CRISÓSTOMO, J. R.; FREITAS, J. de A. D. de; HOLANDA, J. S. de; CARDOSO, J. W.;
COSTA, N. D. Adubação, irrigação, híbridos e práticas culturais para o meloeiro no Nordeste. Fortaleza: Embrapa Agroindústria Tropical, 2002. 21p. (Circular Técnica, 14).

DIAS, R. de C. S.; COSTA, D. N.; QUEIROZ, M. A. de; FARIA, C. M. B. de.Cultura da melancia. Petrolina: Embrapa Semiárido, 2001. 20p. (Circular Técnica, 63).

FAGERIA, N. F. Otimização da eficiência nutricional na produção das culturas. Revista Brasileira de Engenharia Agrícola e Ambiental, Campina Grande, v. 2, n. 1, p. 6-16, 1998.

FERNANDES, F. M., PRADO, R. M. Fertirrigação da cultura da melancia. In: BOARETTO, A. E.; VILLAS BOAS, R. L.; SOUZA, W. F. PARRA, L. R. V. Fertirrigação: teoria e prática. Piracicaba, v. 1, p. 632-653, 2004.

FORATTO, L. C.; ZANINI, J. R.; NATALE,W. Teor de fósforo e $\mathrm{pH}$ no bulbo molhado, com diferentes frequências de fertirrigação, utilizando ácido fosfórico. Engenharia Agrícola, v. 27, n. 2, p. 436-444, 2007.

GRANT, C. A.; FLATEN, D. N.; TOMASIEWICZ, D. J.; SHEPPARD, S. C. A importância do fósforo no desenvolvimento inicial da planta. Piracicaba: Potafos. 16p, 2001. (Informações Agronômicas, 95).

MIRANDA, F. R DE; OLIVEIRA, J. J. G.; SOUZA, F. de. Evapotranspiração máxima e coeficientes de cultivo para a cultura da melancia irrigada por gotejamento. Revista Ciência Agronômica, Fortaleza, v. 35, n. 1, p. 36-43, 2004.

MORAIS, N. B. de; BEZERRA, F. M. L.; MEDEIROS, J. F. de; CHAVES, S. W. P. Resposta de plantas de melancia cultivadas sob 
diferentes níveis de água e de nitrogênio. Revista Ciência Agronômica, v. 39, n. 3, p.369-377, 2008.

NOBRE, J. G. A. Respostas da mamona à irrigação e à aplicação de potássio em argissolo vermelho-amarelo. 2007. 75f. Dissertação (Mestrado em Agronomia/Irrigação e Drenagem) - Universidade Federal do Ceará, Fortaleza, 2007.

PAPADOPOULOS, I. Fertirrigação: situação atual e perspectivas para $o$ futuro. Fertirrigação: Citrus, flores, hortaliças. Guaíba: Agropecuária, FOLEGATTI, Marcos Vinicius (Coord). cap. 1, p. 11- 74, 1999.

PINTO, J. M.; SOARES, J. M.; PEREIRA, J. R.; CHOUDHURY, E. N.; CHOUDHURY, M. M. Efeitos de períodos e de freqüências da fertirrigação nitrogenada na produção do melão. Pesquisa Agropecuária Brasileira, v.29, p.1345-1350. 1994.

ROCHA, M. R. Sistemas de cultivo para a cultura da melancia. 2010. 76f. Dissertação (Mestrado em Ciência do Solo) - Universidade Federal de Santa Maria, Santa Maria, 2010.

SANTORO, B. DE L.; SATO, M. L.; BRUNHARA, J. P. B.; PERES, J. G.; SOUZA,
C. F. Monitoramento da distribuição de uma solução no solo via fertirrigação por gotejamento. Irriga, v.18, n.3, p.572-586, 2013.

SANTOS G. R.; CASTRO NETO M. D.; ALMEIDA H. S. M.; RAMOS L.N.; SARMENTO R. A. ; LIMA S. O. ; ERASMO E.A.L. Effect of nitrogen doses on disease severity and watermelon yield. Horticultura Brasileira, v.27, n.3, p.330-334. 2009.

SARAIVA, K. R. Validação e aplicação prática do modelo "ISAREG" no manejo da irrigação da cultura da melancia no perímetro irrigado Baixo Acaraú, Ceará. 2010. 174 f. Dissertação (Mestrado em Engenharia Agrícola) - Universidade Federal do Ceará, Fortaleza 2010.

SOUZA, D. L. R. Estudo das vantagens competitivas do melão no Ceará. Fortaleza: Instituto Agropólos, 56p. 2006.

ZANINI, J. R.; BARRETO, A. K. G.; FORATTO, L. C.; NATALE,W. Distribuição de fósforo no bulbo molhado, aplicado via fertirrigação por gotejamento com ácido fosfórico. Engenharia Agrícola, v. 27, n. 1, p. 180-193, 2007. 